\title{
The Effect of Arabian Coffee, Black Tea and Orange-juice on Microhardness and Color Stability of Hybrid Composite Resins An in vitro Study
}

\author{
MOHAMMED A. AL-QARNI ${ }^{1}$, GOTAM DAS ${ }^{2}$, SHAHABE SAQUIB ${ }^{3}$, \\ MUHAMMAD SIBGHATULLAH ${ }^{4}$, MANEA MUSA ALAHMARI ${ }^{3}$, SURAJ ARORA ${ }^{4}$ \\ ${ }^{1}$ Department of Restorative Sciences, College of Dentistry, King Khalid University, Abha, Kingdom of Saudi Arabia \\ ${ }^{2}$ Department of Prosthodontics, College of Dentistry, King Khalid University, Abha, Kingdom of Saudi Arabia \\ ${ }^{3}$ Department of Periodontics and Community Dental Sciences, College of Dentistry, King Khalid University, Abha, Kingdom \\ of Saudi Arabia \\ ${ }^{4}$ Department of Restorative Sciences, College of Dentistry, King Khalid University, Abha, Kingdom of Saudi Arabia
}

\begin{abstract}
The main aim of the present in-vitro study is to assess the effect of daily consumable drinks on the aesthetics of the dental composite resin materials. Sixty-four microhybrid and nanohybrid direct composite resin (3M ${ }^{\mathrm{TM}}$ Filtek $^{\mathrm{TM}}$ Z350 XT Universal Restorative, Filtek ${ }^{\mathrm{TM}}$ Bulk Fill Flowable Restorative, USA) block samples were made with a dimension of $15 \mathrm{~mm} X 2 \mathrm{~mm}$ and were allocated into four groups. Each sample was immersed in test media such as Arabic coffee, black tea, orange-juice and distilled water as control group at room temperature for 15 days $(n=16)$. The color stability and microhardness measurements were taken at pre-immersion and after two weeks of immersion in test media. These parameters were assessed by electro spectrophotometer using the CIE (Commission Internationale de l'Eclairage) system and Vickers microhardness indenter respectively. Each group was immersed in its test media for the complete duration of the study. On completion of 15 days, the samples were blot dried out with absorbent paper and microhardness dimensions and color stability measures were performed. The collected data was subjected to statistical analysis to formulate the results. Significant discoloration was observed with the Arabic coffee, black tea and orange-juice compared with control group. The Arabic coffee caused most significant discoloration followed by black tea and orange-juice. Althought the highest values of microhardness were noted in the Arabic coffee followed by black te a and orange juice, whereas the lowest values were noted in the control. Some of the everyday drinks affect the color stability and microhardness of the composite resin restorations more than the others.
\end{abstract}

Keywords: discoloration, microhardness, resin composite, spectrophotometer, beverages

\section{Introduction}

Composite resins are frequently used for direct restorations, on account of the good physical, mechanical, as well as the esthetic properties. The composite restorations are difficult, technique sensitive and time consuming. The inadequate depth to cure is the main cause of composite restoration failure $[1,2]$. The frequently usage of an incremental procedure of universal composites for anterior as well as posterior restorations makes it crucial for the longevity of the material [2].

Composition of resin composite mainly consists of a matrix of plastic resin that binds to filler particles of different sizes [3]. Fibers are discrete in the matrix and coupling agent promotes bonding. Changes in the basic composition of dental composites can give a range of composites with various handling properties [4]. It is reported that surface microhardness is a major property of composite in the success of dental restorations [5].

Dental restorations used in dentistry need a long-term performance in the oral cavity. The surface microhardness of the composite is determined by its resistance to indentations when a particular force is applied in specific time. It has been shown that microhardness is an indicator of degree of polymerization

*email:drgotam2000@gmail.com 
of dental composites. The degree of polymerization is related to the clinical performance of composite restorations [6].

Change in color of dental resin composite is one of the main cause of restoration needing replacement [7]. Chemical changes in the resin matrix, for example oxidation of unpolymerized monomers and amine accelerators, are intrinsic factors resulting resin composite staining [2, 3]. Deposition of bacterial plaque and absorption of stains from various foodstuffs and drinks are the most common extrinsic agents for discoloration $[4,5]$.

From years, nano and microfilled resin composites with different filler sizes varying from 0.02 to $0.04 \mu \mathrm{m}$ have had the smoothest finish, but weak mechanical properties have restricted their application due to decreased filler material $[8,9]$. By adding the advantages of nano and micro hybrid dental composite materials we can achieve a good physical properties and a smooth finish. This modification in the formulation of dental composites of enhanced filler content and decreased particle size of the fillers produced hybrid types of nano and micro fillers. It has been found that the blend of nano and micro fillers decreases the gap between the filler particles giving the highest filler load, causing in improved longevity and the surface polish [10].

Dental composite accomplishes deep depth of curing by employing distinctive composition. This special chemistry may affect the characteristics of the resins [11]. Although composites are commonly considered for posterior teeth restorations, microhardness and color stability might affect the longevity of resin restorations including the dentist's choice for alternative restoration. Shade selection and morphology of tooth (consists of resistance to abrasion) are crucial to provide the service of dental composites, and these two important variables are used to assess the quality of resin composites based on the United Stated Public Health System (USPHS) [12].

Dental composites are exposed to external stains in the mouth from different sources such as drinks, foods and smoking [13-15]. It is very crucial to evaluate the effect of discoloration and microhardness on the resin composite restoration. Thus, objective of the study is to evaluate microhardness and color stability of two types of resin composite materials: microhybrid (MH) composite resins and the newer nanofilled (NF) composite resins after immersion in commonly consumed beverages in the Kingdom of Saudi Arabia.

\section{Materials and methods}

\subsection{Specimen preparation}

Two types of dental composite materials: $\left(3 \mathrm{M}^{\mathrm{TM}}\right.$ Filtek ${ }^{\mathrm{TM}} \mathrm{Z} 350$ XT Universal Restorative, and $3 \mathrm{M}^{\mathrm{TM}}$ Filtek $^{\mathrm{TM}}$ Bulk Fill Flowable Restorative). Sixty-four samples (15 mm in diameter and $2 \mathrm{~mm}$ in thickness) were prepared from each resin material by the stainless-steel mold and light cured for 20s using LED (3M ${ }^{\mathrm{TM}}$ Elipar ${ }^{\mathrm{TM}}$ Deep Cure-S LED Curing Light, USA). Samples were divided into eight groups and each group contained eight samples (Figure 1). Materials I and II had four groups each. In each group, 4 samples were randomly selected for microhardness testing and the remaining 4 for color stability. Baseline measurements were made for all the samples following post-immersion of $24 \mathrm{~h}$ in water. After baseline measurements, the samples were immersed in the test media for 15 days, followed by final testing in the lab. 

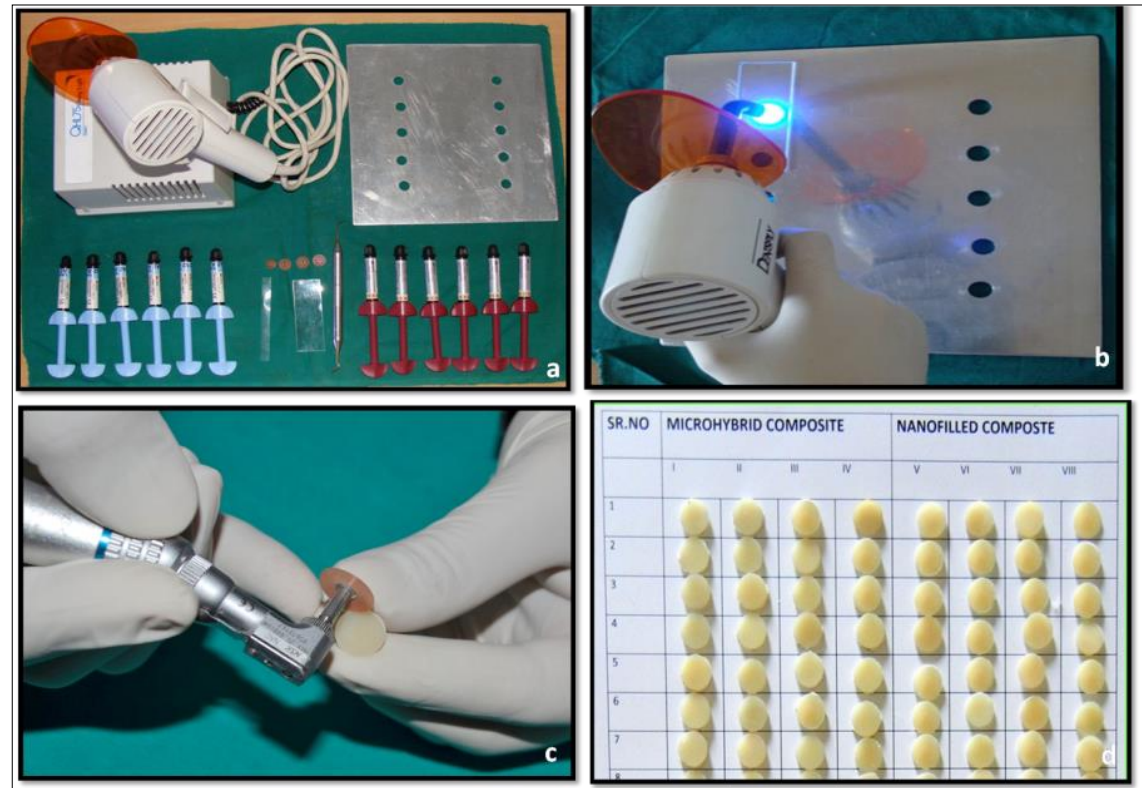

Figure 1. Sample preparation a) Armamentarium, b) Curing of the material, c) Finishing of the sample with soflex finishing kit, and d) Completed samples of microhybrid and nanofilled composites

\subsection{Test media preparation}

Arabic coffee solution was prepared by immersion of a sachet into $300 \mathrm{~mL}$ of the boiling distilled water as per the manufacturer's instructions for $10 \mathrm{~min}$. The tea solution was formed by immersion of two prefabricated tea bags $(2 \times 2 \mathrm{~g})$ into $300 \mathrm{~mL}$ of boiling distilled water for $10 \mathrm{~min}$. Orange-juice solution was prepared by $250 \mathrm{~mL}$ packet available in market. In control group samples were kept in distilled water which acted as control. The solutions were replaced daily during the 15 days course of the study.

\subsection{Microhardness Measurement}

Vickers microhardness values were achieved by testing the samples before and after 15 days of immersion in the solutions. For every measurement, two indentations were formed in every sample by applying a 5 Newton continuous load for 20s in a microhardness tester (Intelligent Micro Vickers Hardness Tester - QIV-1000Z, USA) (Figure 2a). Standard Vickers microhardness values were measured for each group.

\subsection{Color stability testing:}

The color was measured following the CIE (Commission Internationale de 1'Eclairage) L*a*b* system. In this study elecrtospectrophotometer (Spectrophotometer NANOCOLOR VIS II France) was used for color measurement. (Figure 2b). This device lamps with 10 different colors held in round, which directs a light bundle at $45^{\circ}$, which records and captures the $\mathrm{L}^{*}, \mathrm{a}^{*}$ and $\mathrm{b}^{*}$ significance of every sample. The axis $\mathrm{L}^{*}$ relays to the lightness synchronize and its rate ranges from zero (black) to 100 (white). The axis $\mathrm{a}^{*}$ and $\mathrm{b}^{*}$ chromaticity synchronize in the red-green and yellow-blue axis, respectively. Positive $\mathrm{a}^{*}$ values nominated as a shift to red and negative values nominated a shift to green. Moreover, negative $b^{*}$ measurements show the blue color range and positive $b^{*}$ values indicate the yellow color range. Subsequent to basic color values, the samples were kept in various solutions.

After 15 days of immersion in the solutions, the samples were rinsed with distilled water for 5 min and blotted dry with absorbent paper prior to the second color measurement and microhardness evaluation. Color changes $(\Delta \mathrm{E})$ among baseline and post 15 days immersion were measured by using the following equation: 


$$
\Delta \mathrm{E}=\left[(\mathrm{L} *)^{2}+(\mathrm{a} *)^{2}+\left(\mathrm{b}^{*}\right)^{2}\right]^{1 / 2}
$$
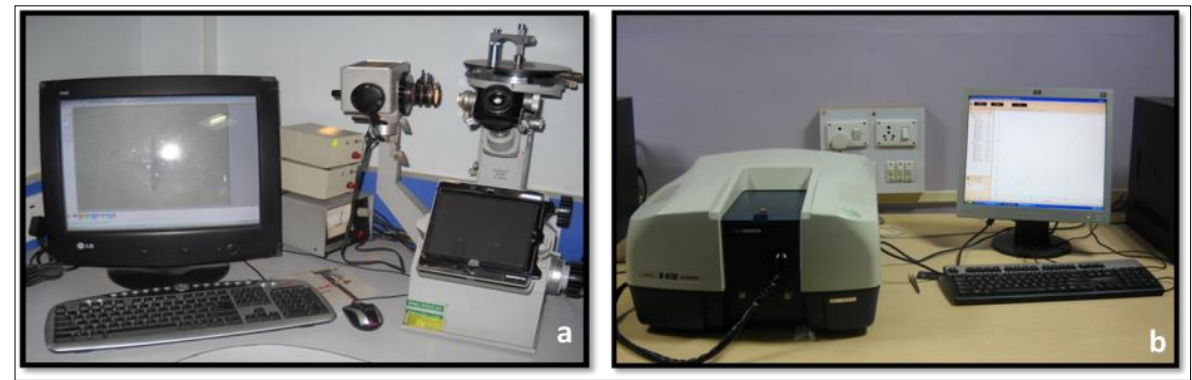

Figure 2. a) Vickers microhardness testing machine and b) Electro-spectrophotometer

\section{Results and discussions}

Statistical software (SPSS version 23, BM Corporation, NY; USA) was used to analyze the data. The microhardness values were evaluated by using an independent sample ' $t$ ' test. P-values were achieved by one-way analysis of variance (ANOVA) using Tukey's for different group assessment. A p-value (P < $0.05)$ is statistically significant.

Percentage variation in microhardness is evaluated by the below equation:

$$
\frac{\text { Microhardness Before }- \text { Microhardness After }}{\text { Microhardness Before }} \times 100
$$

A paired t-test was used for the evaluation of microhardness of material I and II within every group after immersing into test solution (Table 2). For material I and II, microhardness values considerably reduced in all the groups following exposure to the solution. Moreover, the \% change in microhardness for material I and II was evaluated in various solutions as shown in Figure 3. The change of color was observed between two the materials in different beverages as revealed in figure 4. Statistical evaluation revealed that $\%$ change in surface microhardness was not significant among the Arabic coffee, black tea, orange-juice and water, although the change in $\%$ of microhardness was significantly more in material II compared to material I as indicated in figure 5. The standard fraction change in microhardness for both materials was considerably more in Arabic coffee than all other groups (Table 1).

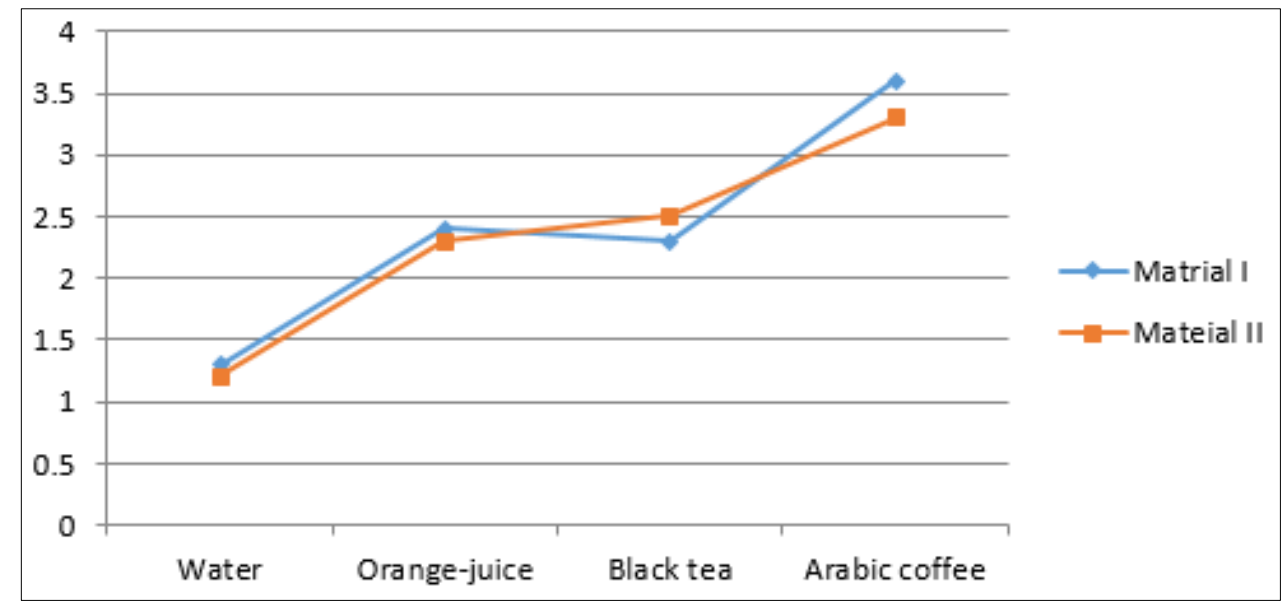

Figure 3. The distribution of change in microhardness between two materials in each beverage type 
Table 1. Comparison of microhardness within each group after immersion in beverage

\begin{tabular}{|c|c|c|c|c|c|c|}
\hline & \multicolumn{2}{|c|}{ Material I (n=32) [Microhybrid] } & \multicolumn{2}{c|}{ Material II (n=32) [Nanofilled] } \\
\hline Beverage & Before & After & P-value & Before & After & P-value \\
\hline Water (Control) $(\mathrm{n}=15)$ & $68.1 \pm 2.6$ & $66.1 \pm 2.8$ & $0.001^{*}$ & $67.5 \pm 2.4$ & $62.3 \pm 2.7$ & $0.001^{*}$ \\
\hline Orange-juice $(\mathrm{n}=15)$ & $69.6 \pm 2.9$ & $67.5 \pm 2.5$ & $0.001^{*}$ & $68.1 \pm 6.2$ & $65.5 \pm 6.8$ & $0.011^{*}$ \\
\hline Black tea $(\mathrm{n}=15)$ & $69.7 \pm 2.3$ & $63.1 \pm 2.6$ & $0.001^{*}$ & $67.7 \pm 3.1$ & $64.7 \pm 4.0$ & $0.009^{*}$ \\
\hline Arabic coffee $(\mathrm{n}=15)$ & $68.4 \pm 2.4$ & $62.7 \pm 3.2$ & $0.001^{*}$ & $67.6 \pm 2.4$ & $58.1 \pm 4.4$ & $0.001^{*}$ \\
\hline
\end{tabular}
P-value by paired t test (paired analysis). P-value<0.05 is considered to be statistically significant.

The calculation of color change for both materials was evaluated in various solutions (Figure 4). Color alternation was noted considerably more in material II in contrast to material I when immersed into Arabic coffee and water, respectively. Statistically, a less considerable difference was noted among two composites when put into black tea and orange-juice. Statistical assessment within each material for the fraction in color (as measured by $\Delta \mathrm{E}$ ) explained that both materials I and II had a statistically significant difference between all the groups except orange-juice and water (Table 2). Average $\Delta \mathrm{E}$ value for both materials I and II were significantly higher in Arabic coffee and black tea compared to the water and orange-juice Table 3. Comparison of change in microhardness and change in colour was within material Table 4.

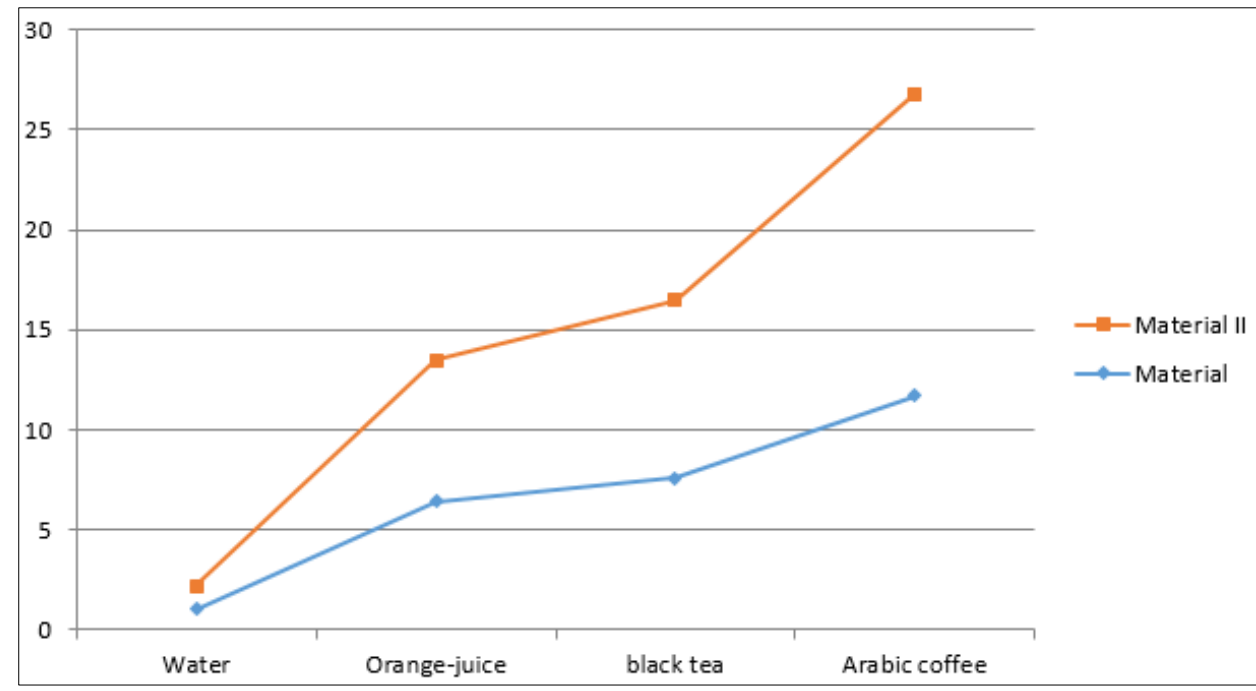

Figure 4. The distribution of change in color between two materials in each beverage type

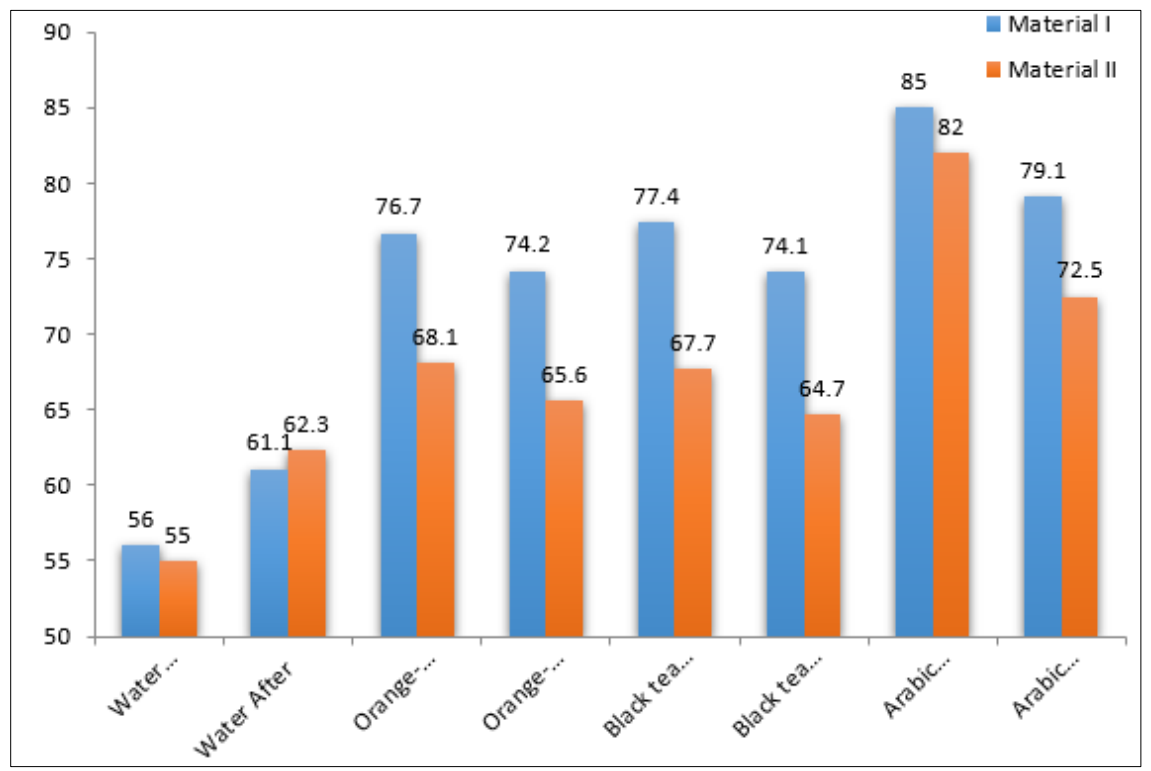

Figure 5. Comparison of microhardness of each material within each group 
Table 2. Between group distribution of change in microhardness and change in colour (as measured by $\Delta \mathrm{E}$ ) between two materials in each beverage type

\begin{tabular}{|c|c|c|c|c|c|c|c|c|}
\hline & \multicolumn{3}{|c|}{ Material I (n=32) [Microhybrid] } & \multicolumn{4}{c|}{ Material II (n=32) [Nanofilled] } \\
\hline & $\begin{array}{c}\text { Water } \\
\text { (Control) }\end{array}$ & $\begin{array}{c}\text { Orange- } \\
\text { juice }\end{array}$ & Black tea & $\begin{array}{c}\text { Arabic } \\
\text { coffee }\end{array}$ & $\begin{array}{c}\text { Water } \\
\text { (Control) }\end{array}$ & $\begin{array}{c}\text { Orange- } \\
\text { juice }\end{array}$ & Black tea & $\begin{array}{c}\text { Arabic } \\
\text { coffee }\end{array}$ \\
\hline $\begin{array}{c}\text { \% Change in } \\
\text { Microhardness }\end{array}$ & $0.9 \pm 0.2$ & $4.5 \pm 2.3$ & $5.0 \pm 2.2$ & $11.3 \pm 3.1$ & $2.9 \pm 1.1$ & $4.1 \pm 2.3$ & $4.9 \pm 2.1$ & $15.2 \pm 4.7$ \\
\hline $\begin{array}{c}\text { Change in colour } \\
(\Delta \mathrm{E})\end{array}$ & $1.1 \pm 0.5$ & $6.8 \pm 2.2$ & $12.1 \pm 2.9$ & $13.4 \pm 2.9$ & $1.4 \pm 0.7$ & $10.1 \pm 2.5$ & $12.7 \pm 3.1$ & $14.8 \pm 2.8$ \\
\hline
\end{tabular}

Values are \pm mean standard deviation of microhardness and colour stability.

Table 3. Between material statistical comparison of change in microhardness and change in colour (as measured by $\Delta \mathrm{E}$ ) in each beverage type

\begin{tabular}{|c|c|c|c|c|}
\hline & Water (Control) & Orange-juice & Black tea & Arabic coffee \\
\hline & $\begin{array}{c}\text { Material I vs } \\
\text { Material II }\end{array}$ & $\begin{array}{c}\text { Material I vs } \\
\text { Material II }\end{array}$ & $\begin{array}{c}\text { Material I vs } \\
\text { Material II }\end{array}$ & $\begin{array}{c}\text { Material I vs } \\
\text { Material II }\end{array}$ \\
\hline $\begin{array}{c}\% \text { Change in } \\
\text { Microhardness }\end{array}$ & 0.321 & 0.634 & 0.937 & $0.007^{*}$ \\
\hline $\begin{array}{c}\text { Change in colour } \\
(\Delta \mathrm{E})\end{array}$ & $0.011^{*}$ & 0.218 & $0.018^{*}$ & 0.118 \\
\hline
\end{tabular}

Values are mean standard deviation of microhardness. P-value by independent sample ' $t$ ' test. P-value $=0.05$ is considered to be statistically significant. ${ }^{*}$ denotes significant.

Table 4. Within material statistical comparison of change in microhardness and change in colour (as measured by $\Delta \mathrm{E}$ )

\begin{tabular}{|c|c|c|c|c|c|c|}
\hline & \multicolumn{5}{|c|}{ MaterialI } \\
\hline & $\begin{array}{c}\text { Water vs } \\
\text { orange-juice }\end{array}$ & $\begin{array}{c}\text { Water vs } \\
\text { Black tea }\end{array}$ & $\begin{array}{c}\text { Water vs } \\
\text { Arabic } \\
\text { coffee }\end{array}$ & $\begin{array}{c}\text { orange-juice } \\
\text { vs Black tea }\end{array}$ & $\begin{array}{c}\text { orange- } \\
\text { juice vs } \\
\text { Arabic } \\
\text { coffee }\end{array}$ & $\begin{array}{c}\text { Black tea } \\
\text { vs Arabic } \\
\text { coffee }\end{array}$ \\
\hline $\begin{array}{c}\text { \% Change in } \\
\text { Microhardness }\end{array}$ & 0.321 & $0.016^{*}$ & $0.001^{*}$ & 0.531 & $0.001^{*}$ & $0.001^{*}$ \\
\hline $\begin{array}{c}\text { Change in color } \\
(\Delta \mathrm{E})\end{array}$ & $0.001^{*}$ & $0.001^{*}$ & 0.090 & $0.001^{*}$ & $0.001^{*}$ & $0.001^{*}$ \\
\hline & \multicolumn{7}{|c|}{ Material II } & Water vs & orange-juice & $\begin{array}{c}\text { orange- } \\
\text { juice vs } \\
\text { Arabic } \\
\text { coffee }\end{array}$ & $\begin{array}{c}\text { Black tea } \\
\text { vs Arabic } \\
\text { coffee }\end{array}$ \\
\hline $\begin{array}{c}\% \text { Change in } \\
\text { Microhardness }\end{array}$ & 0.937 & 0.634 & $0.001^{*}$ & 0.952 & $0.001^{*}$ & $0.012^{*}$ \\
\hline $\begin{array}{c}\text { Change in color } \\
(\Delta \mathrm{E})\end{array}$ & $0.001^{*}$ & $0.001^{*}$ & 0.137 & $0.001^{*}$ & $0.001^{*}$ & $0.001^{*}$ \\
\hline
\end{tabular}

Values are mean standard deviation of microhardness.

P-values are obtained by one-way analysis of variance (ANOVA) using Tukey's correction for multiple group comparisons.

$P$-value $<0.05$ is considered to be statistically significant. * denotes significant.

Different types of color measurement tools have been designed to decrease the probable mistakes. Thereby, it was likely to analyze $\Delta \mathrm{E}$ values by means of color parameters in the CELAB color method. To reduce the potential problem in color evaluation the current study used the spectrometer for color parameters. Ozkanogluet al. [16] showed that mainly staining take place during the $1^{\text {st }}$ week of immersion. Based on these results, the current study used resin composites which were placed in the 
media for 15 days, $1^{\text {st }}$ week for staining and $2^{\text {nd }}$ week for stabilization of the resin composite. Composite resin was stained and stabilized for the discoloration after 15 days of immersion in the solutions. Guler et al., reported that the normal time for drinking of one cup of coffee is fifteen minutes and between coffee consumers, the normal use is 3.2 cups each day. Consequently, 2 weeks of storage simulated consumption of the drink around one year [17].

The solution was changed each day. In earlier studies, the clinically satisfactory color change threshold values were established as $\Delta \mathrm{E} \leq 3.3[15,16]$. The outcomes of present study, the $\Delta \mathrm{E}$ values of composite material measured in Arabic coffee, black tea and orange-juice were reported to be higher than the clinically acceptable levels. According to Guler et al. [17] more the silane coupling agent and resin quantity the more will be the coloration. Consequently, the excess quantity of silane in composite may lead to more coloration. The maximum $\Delta \mathrm{E}$ value in this study was observed in the specimen of composite with Arabic coffee. Nevertheless, these outcomes were observed because of degradation of material and increased values were observed because of higher surface roughness. Um and Ruyter [18] reported that colorants in coffee were attached to the external surface of the composite restoration so the staining from coffee was more pronounced.

The outcomes of present study supported many studies with food-simulating liquid that causes softening and increase the wear of dental composites [19,20,21]. With regards to color stability, the results of current study revealed that all the beverages caused staining of composite resins. The staining for microhybrid composite was greatest with specimens immersed in test media such as Arabic coffee (Mean difference $=11.4 \pm 3.0$ ) followed by black tea (Mean difference $=7.8 \pm 1.8$ ), orange-juice (Mean difference $=2.5 \pm 0.6)$ and the least reduction was seen in the specimens immersed in distilled water as control media (Mean difference $=0.9 \pm 0.5$ ). Similarly, for nanofilled also the staining was greatest with specimens immersed in test media such as Arabic coffee (Mean difference $=14.4 \pm 2.8$ ) followed by black tea (Mean difference $=9.0 \pm 2.3$ ), orange-juice (Mean difference $=2.9 \pm 0.9$ ) and distilled water as control media (Mean difference $=2.5 \pm 0.6$ ).

In one study by Ozkanogluet al, [16] in which various resin composites were placed in the different solutions for six weeks, author noted that the ability of coffee staining was more than tea and cola, and no variation was found among the two resin composites. Same findings were noted in several studies which indicated that coffee is a more efficient coloring agent than cola and tea. Mundim et al, [22] reported that despite acidic nature of cola, was not potent to change the color of resin composite. In this study it was found that the staining ability of Arabic coffee was more distinct than the black tea, orangejuice and distilled water.

Microhardness is related to structural durability of the composite which is one of the major factors concerned to the longevity of the composite restorations. Decreased microhardness values are frequently related to reduce scratch and wear resistance, which may cause composite restoration breakdown [23, 24]. The microhardness evaluation is calculated in the form of a fixed diamond tip that has been pressed under certain load within specific time period to leave the indentations on the materials. In present study, the Vickers microhardness test was undertaken because it has been used in several earlier studies. Yap et al, [25] founded that the alterations in the microhardness of the chemical conditions were dependent on the type of resin composite. Yeşilyurt et al, [26] concluded that the microhardness values of resins can change significantly in various chemical settings, which is noted to happen in the first two weeks.

Present study showed that all drinks lead to reduction in microhardness of composite material. The reduction in the microhardness for microhybrid resin was higher when samples were placed in Arabic coffee $(($ Mean difference $=10.2 \pm 2.6)$ followed by black tea (Mean difference $=4.3 \pm 1.9)$, orange-juice (Mean difference $=3.2 \pm 2.1$ ) and minimum reduction was observed in the samples placed in distilled water (Mean difference $=1.9 \pm 1.2$ ). Same results were also seen with nanofilled composites; reduction in microhardness was higher with samples placed in Arabic coffee (Mean difference $=14.1 \pm 4.3$ ), followed by black tea (Mean difference $=4.5 \pm 2.0$ ), orange-juice (Mean difference $=3.7 \pm 2.2$ ) and distilled water (Mean difference $=2.7 \pm 1.9$ ). 
Braem et al. [27] and Chung and Greener [28] noted that increase microhardness values were calculated in composite with enhance filler material. Following to the outcomes of present study, the Z350 XT group composite indicated a superior microhardness in contrast to Filtek ${ }^{\mathrm{TM}}$ Bulk Fill which revealed reduced microhardness values. In several studies surface hardness measurements of composite material was done after immersion in various solutions [29-31]. In another study by Yanıkoğlu et al, [19] a reduction was reported in the microhardness of various resin composites after storing in coffee, tea and cola against storing in distilled water. Consequently, the null hypothesis of the study that various beverages would not influence the microhardness and color stability of the composite was rejected.

Bahbishi et al, [1] reported that it is quite hard to differentiate one test media as the major colorant for resin composite or to believe it is a more prone to cause staining in every condition because of variations in chemical composition of composites. Few factors are important for composite color stability such as (1) Composite type (conventional, flowable, and Bulk-Fill), (2) test media type (coffee, tea, cola, juice, berry etc), (3) solution color (darker solutions cause more color), (4) period of immersion (prolonged immersion cause more color changes), and (5) sample thickness (thicker sheets are more suspect to color changes).

In comparison of two composite materials, an outcome of present study showed that microhybrid

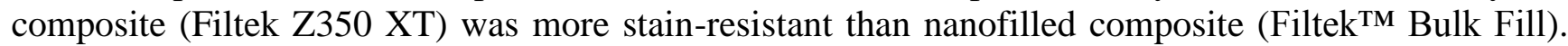
These two resin composites from the same manufacturer have almost the same composition and practically the same filler loading by volume. However, agglomerated particles so-called nanoclusters present in nanofilled composites seemed to be less color-resistant than the zirconia-silica micron-sized fillers present in microhybrid composites, which could be due to the former's relatively high water sorption character. In a previous study, discoloration of nanofilled composite (Supreme) and microhybrid resin composite (Venus) against Arabic coffee, black tea, orange-juice and distilled water, after various types of finishing and polishing operations was evaluated [29]. In agreement with our study, it was found that nanofilled composite showed higher stainability than the microhybrid counterpart, especially when the surface was finished with superfine diamond bur.

\section{Conclusions}

According to the results of present study, within the limitations of our study, the subsequent conclusions were drawn:

Microhardness reduced in both the materials microhybrid and nanofilled composite following immersion in all the tested beverages. While the highest color change among composite resins was observed in Arabic coffee and black tea, it was seen that the Arabic coffee caused more color change than black tea and orange-juice. Change in color was significantly higher in nanofilled composite compared to microhybrid composite in coffee. The values determined in the study reveal the potential for the coloration and microhardness of restorative materials to be affected, but the data obtained should be supported by clinical studies.

Acknowledgments. The authors extend their appreciation to the Deanship of Scientific Research at King Khalid University for funding this work through General Research Project under grant number GRP-7641.

\section{References}

1.BAHBISHI, N., MZAIN, W., BADEEB, B., NASSAR, H.M., Color Stability and Micro-Hardness of Bulk-Fill Composite Materials after Exposure to Common Beverages. Materials, 13(3), 2020, p.787. 2.STRAZZI-SAHYON, H.B., PASSOS ROCHA, E., GONÇALVES ASSUNÇÃO, W., HENRIQUE DOS SANTOS, P., Influence of Light-Curing Intensity on Color Stability and Microhardness of Composite Resins. International Journal of Periodontics \& Restorative Dentistry, 2020, 40(1). 
3.KANG, Y.A., LEE, H.A., CHANG, J., MOON, W., CHUNG, S.H., LIM, B.S., Color Stability of Dental Reinforced CAD/CAM Hybrid Composite Blocks Compared to Regular Blocks. Materials, 13(21), 2020, p.4722.

4.NAIR, S.R., NIRANJAN, N.T., JAYASHEEL, A., SURYAKANTH, D.B., Comparative evaluation of colour stability and surface hardness of methacrylate based Flowable and packable composite-in vitro study. Journal of clinical and diagnostic research: JCDR, 11(3), 2017, p. ZC51.

5.MARIGO, L., NOCCA, G., FIORENZANO, G., CALLÀ, C., CASTAGNOLA, R., CORDARO, M., PAOLONE, G., SAURO, S. Influences of different air-inhibition coatings on monomer release, microhardness, and color stability of two composite materials. BioMed research international, 2019.

6.RAMADAN, A.A., ALI, M.S., BAYOUMI, R.E., Effect of Abrasive Containing Whitening Dentifrices on Surface Characteristics and Color Stability of Two Aesthetic Restorative Materials. AlAzhar Dental Journal for Girls, 7(4 October-Restorative Dentistry issue (Removable Prosthodontics, Fixed Prosthodontics, Endodontics, Dental Biomaterials, Operative Dentistry), 2020, pp.537-546.

7.MENON, A., GANAPATHY, D.M., MALLIKARJUNA, A.V., Factors that influence the colour stability of composite resins. Drug Invention Today, 2019, 11(3).

8.TAVANGAR, M., BAGHERI, R., KWON, T.Y., MESE, A., MANTON, D.J., Influence of beverages and surface roughness on the color change of resin composites. Journal of investigative and clinical dentistry, 9(3), 2018, p.e12333.

9.COLOMBO, M., GALlO, S., POGGIO, C., RICALDONE, V., ARCIOLA, C.R., SCRIBANTE, A., New resin-based bulk-fill composites: In vitro Evaluation of micro-hardness and depth of cure as infection risk indexes. Materials, 13(6), 2020, p.1308.

10.ZAFAR, M.S., KHAN, E., AVERSA, R., PETRESCU, R.V., APICELlA, A., PETRESCU, F.I., Influence of curing light type and staining medium on the discoloring stability of dental restorative composite. American Journal of Biochemistry and Biotechnology, 13(1), 2017, pp.42-50.

11.RAJASEKHAR, R., JAMES, B., JOHNY, M.K., JACOB, J., Evaluation of the effect of two commercially available non-alcoholic mouth rinses on the microhardness of composite material-An invitro study. Dental Journal, 2019, 1(1).

12.TAHER, H.M., ABOUAUF, E.A., The Surface Gloss and Micro-hardness of Two Recent Tooth Colored Restorative Materials After In-office Bleaching. Egyptian Dental Journal, 65(2019, pp.513-521. 13.ANDREEVSKI, A., KOVACEVSKA, I., The effect of every day drinks on composite restorations aesthetics: in vitro study. IOSR Journal of Dental and Medical Sciences (IOSR-JDMS), 2020.

14.CHOI, J.W., LEE, M.J., OH, S.H., KIM, K.M., Changes in the physical properties and color stability of aesthetic restorative materials caused by various beverages. Dental materials journal, 38(1), 2019, pp.33-40.

15.CANGUL, S., ERPACAL, B., ADIGUZEL, O., UNAL, M., GUNAY, A., Effect of Surface Wetting Resin on the Color Stability and Microhardness of Esthetic Composites. Odovtos-International Journal of Dental Sciences, 2021, pp.285-292.

16.OZKANOGLU, S., AKIN, E.G., Evaluation of the effect of various beverages on the color stability and microhardness of restorative materials. Nigerian journal of clinical practice, 23(3), 2020, p.322.

17.GÜLER, A.U., GÜLER, E., YÜCEL, A.Ç., ERTAŞ, E., Effects of polishing procedures on color stability of composite resins. Journal of Applied Oral Science, 17(2), pp.108-112.

18.UM, C.M., RUYTER, I., Staining of resin-based veneering materials with coffee and tea. Quintessence international, 1991, 22(5).

19.NURAN YANIKOĞLU. Effects of different solutions on the surface hardness of composite resin materials. Dent Mater J., 28(3), 2009, pp.344-51.

20.ERTAŞ E, GÜLER A.U., YÜCEL A.C, KÖPRÜLÜ H, GÜLER E., Color stability of resin composites after immersion in different drinks. Dent Mater J., 25(2), 2006, 371-6.

21.MUHITTIN, U., BURAK, T.U., KAM, H.O. Color Stability of Microhybrid and Nanofilled Composite Resins: Effect of Surface Sealant Agents Containing Different Filler Content. The journal of contemporary dental practice, 20(9), 2019, p.1046. 
22.MUNDIM, F.M., GARCIA, L.D.F.R., PIRES-DE-SOUZA, F.D.C.P., Effect of staining solutions and repolishing on color stability of direct composites. Journal of Applied Oral Science, 18(3), 2010, p.249254.

23.FUGOLIN, A.P., DOBSON, A., MBIYA, W., NAVARRO, O., FERRACANE, J.L., PFEIFER, C.S., Use of (meth) acrylamides as alternative monomers in dental adhesive systems. Dental Materials, 35(5), 2019, pp.686-696.

24.SUNBUL HA, SILIKAS N, WATTS DC., Surface and bulk properties of dental resin- composites after solvent storage. Dent Mater., 32(8), 2016, pp. 987-97.

25.YAP, A.U.J., TAN, S.H.L., WEE, S.S.C., LEE, C.W., LIM, E.L.C., ZENG, K.Y. Chemical degradation of composite restoratives. Journal of Oral Rehabilitation, 28(11), 2001, pp.1015-1021.

26.YESILYURT, C., YOLDAS, O., ALTINTAS, S.H., KUSGOZ, A., Effects of food-simulating liquids on the mechanical properties of a silorane-based dental composite. Dental materials journal, 28(3), 2009, pp.362-367.

27.BRAEM, M., FINGER, W., VAN DOREN, V.E., LAMBRECHTS, P., VANHERLE, G., Mechanical properties and filler fraction of dental composites. Dental Materials, 5(5), 1989, pp.346-349.

28.CHUNG, K.H., GREENER, E.H., Correlation between degree of conversion, filler concentration and mechanical properties of posterior composite resins. Journal of oral rehabilitation, 17(5), 1990, pp.487494.

29.KOC-VURAL U, BALTACIOGLU I, ALTINCI P., Colorstability of bulk-fill and incremental-fill resin-based composites polished with aluminum-oxide impregnated disks.Restor Dent Endod., 42(2), 2017, pp. 118-124.

30.SHETTY, P., PURAYIL, T.P., GINJUPALLI, K., PENTAPATI, K.C., Effect of polishing technique and immersion in beverages on color stability of nanoceramic composites. Journal of Oral Biology and Craniofacial Research, 11(1), 2021, pp.53-56.

31.DE ANDRADE, I.C.G.B., BASTING, R.T., RODRIGUES, J.A., DO AMARAL, F.L.B., TURSSI, C.P., FRANÇA, F.M.G., Microhardness and color monitoring of nanofilled resin composite after bleaching and staining. European journal of dentistry, 8(2), 2014, p.160.

Manuscript received: 7.06.2020 